\title{
Investigation for Remediation of Selenium Aqueous Environment with Using Organic Pillared Bentonite by Radiotracer Technique
}

\author{
A.B.Tugrul*, S.Haciyakupoglu, S. Erenturk, N. Karatepe, F.Baytas, N.Baydogan, \\ N.Altinsoy, B.Buyuk, E.Orucoglu, E.Demir, Z.Camtakan, M.OkKa \\ Istanbul Technical University, Energy Institute, ITU Ayazaga Campus, 34469, Sariyer, Istanbul, Turkey
}

\begin{abstract}
In this study remediation of selenium ions from aqueous solutions was investigated using organic pillared bentonite as an adsorbent. Organic pillared bentonite was produced from Resadiye (Tokat, Turkey) bentonite using hexadecylpyridinium chloride and aluminum polyoxy-cations. All the experiments were carried out by tracing with selenium radioisotope. For the production of the radioactive selenium radioisotope, selenium dioxide was irradiated in the central thimble of ITU TRIGA Mark II Training and Research Reactor at Energy Institute of Istanbul Technical University. Radioactivity measurements carried out by the gamma-ray spectroscopy system were used to determine of selenium isotope. The relative importance of test parameters like concentration of adsorbate, $\mathrm{pH}$ of the solution and contact time on adsorption performance of organic pillared bentonite for selenium ion was studied. Evaluation of experiments for different parameters showed possibility of remediation of selenium from aqueous media by using organic pillared bentonite.
\end{abstract}

DOI: 10.12693 /APhysPolA.127.1186

PACS: 25.20.Dc

\section{Introduction}

In nature, selenium is an essential element for humans and animals so as that it is used as a nutritional additive element. It should be controled with regard to both toxicity and deficiencies in humans and livestock. Therefore, adverse effects on human health occur from both too much and from too little exposure to selenium. Selenium is also known to be mutagenic and teratogenic. Selenium is introduced in the environment from different sources, both natural and anthropogenic [1]. Selenium mobility in the environment, availability for biota and toxicity depends on its oxidation state and so its speciation is necessary. In the environment, selenium can exist in different oxidation states, elemental selenium (Se), selenite $\left(\mathrm{SeO}_{3}^{2-}\right)$, selenide $\left(\mathrm{Se}^{2-}\right)$, selenate $\left(\mathrm{SeO}_{4}^{2-}\right)$ and organic selenium. Selenite and selenate are found to be thermodynamically stable under the $\mathrm{pH}$ and redox conditions that are found in most aqueous media and are the predominant chemical forms. Selenite is present in mildly oxidizing, neutral $\mathrm{pH}$ environments and typical humid regions. Selenate is the predominant form under ordinary alkaline and oxidized conditions [1-3].

The presence of selenium in waste and surface waters is becoming a severe environmental and public health problem. A variety of treatment technologies have been reported for selenium removal from contaminated waters [4-8]. Aqueous environment is a source media for selenium. Because of the toxicity of selenium and its

${ }^{*}$ corresponding author; e-mail: beril@itu.edu.tr inorganic compounds generally ought to necessary remediation from the different media.

The most widely used methods for removing selenium from wastewaters include ion-exchange, chemical precipitation, reverse osmosis, evaporation, membrane filtration, adsorption, and biosorption [4, 9, 10]. Among these technologies, adsorption onto bentonite is one of the most effective and reliable technologies for wastewater treatment. In general, bentonites are broadly applied effective adsorbents for wastewater treatment. In this study, organic pillared bentonite was prepared and adsorption of selenium from aqueous solution was studied as a function of the initial selenium concentration, $\mathrm{pH}$ and shaking time.

\section{Experimental}

All chemicals used in this work, were of analytical reagent grade and used without further purification. All reagents were evaluated for their contribution to selenium contamination in the blanks. Bidistilled water was used through all experiments for dilutions and standard preparations.

In order to prepare organo-inorgano pillared bentonite, first of all the aluminum polyoxy-cations were synthesized. 0.4 M NaOH solution was added very slowly into $0.4 \mathrm{M} \mathrm{AlCl} 3 \cdot 6 \mathrm{H}_{2} \mathrm{O}$ solution satisfying $2.62 \mathrm{Al} / \mathrm{OH}$ and $20 \mathrm{mmol} \mathrm{Al} /$ clay ratios and stirred $24 \mathrm{~h}$ at $40^{\circ} \mathrm{C}$. Then, the prepared solution was aged for $24 \mathrm{~h}$. The solution was clear and precipitation was not observed. This solution and organic solution, which was prepared by using hexadecylpyridinium chloride monohydrate (150\% CEC of purified bentonite), were added drop wise into bentonite suspension having $2 \%$ solid to liquid mass ratio. To satisfy homogeneous intercalation of organic and inorganic 
cations into bentonite, the suspension was stirred during addition of the solutions. After the dropping operation was completed, stirring was continued for 3 hours. After aging 2 days, the mixture was washed and filtered to remove the excess ions and $\mathrm{Cl}$ anions from the modified bentonite. This procedure was continued until to reach constant conductivity at $37 \mu \mathrm{Scm}^{-1}$. The obtained filtered material was put into an oven at $40^{\circ} \mathrm{C}$ for a night.

Original selenium dioxide compound was packed in polyethylene tube and irradiated in central irradiation tube of TRIGA Mark II Training and Research Reactor at Istanbul Technical University at $250 \mathrm{~kW}$ for 1 hour. By this neutron bombardment the following reaction occurs for selenium-74 isotopes and radioactive selenium-75 $\left({ }^{75} \mathrm{Se}\right)$ with 119.769 day half-life was produced [11-13].

Scintillation detector $(2 \times 2$ in $\mathrm{NaI}(\mathrm{Tl})$, Canberra)was used to determine ${ }^{75}$ Se radioisotope activities of the samples. The detector, with the integrated digital gamma spectrometer (digiBASE model PMT) has $8.5 \%$ resolution for $0.662 \mathrm{MeV}$ of ${ }^{137} \mathrm{Cs}$. Peak areas of ${ }^{75} \mathrm{Se}$ at $136 \mathrm{keV}$ gamma-rays in the spectrums were determined by using MAESTRO-32MCA software program [13-15]. ${ }^{137} \mathrm{Cs}$ and ${ }^{60} \mathrm{Co}$ standard point sources were used in energy calibrations of the spectra (DKD-K-36901-000386, 2006). Counting time was applied as $30 \mathrm{~min}$.

Adsorption studies were carried out by batch technique to obtain the equilibrium data. The stock solution of selenium (IV) $(356 \mathrm{mg} / \mathrm{L})$ was prepared by dissolving appropriate amounts of irradiated selenium dioxide compound $\left(\mathrm{SeO}_{2}\right.$, Fluka, $99 \%$ purity). The experiments were carried out by agitating $2 \mathrm{~mL}$ of solution containing different concentrations of selenium in a thermostated shaker bath (Nuve) with $40 \mathrm{mg}$ of OPBfor various initial concentrations of selenium solution, contact time and $\mathrm{pH}$. Batch adsorption experiments were carried out with a constant shaking rate $250 \mathrm{rpm} / \mathrm{min}$. All experiments were performed at $293 \mathrm{~K}$ and in duplicate. Following separation of solid phase from liquid, samples were centrifuged at $5000 \mathrm{rpm}$ for $5 \mathrm{~min}$. After this step, $1 \mathrm{~mL}$ of each initial adsorption solution and separated solution was transferred in polyethylene tubes for activity measurement at gamma spectrometry system. The amount of adsorbed selenium was estimated from the difference between the initial and final relative activities of selenium. The adsorption amount of selenium from aqueous solution was computed as follows:

$$
A=\left(C_{i}-C_{e}\right) V / m_{A C},
$$

where $A$; adsorbed Se amount (mg Se/g OPB) $C_{i}$ : initial Se concentration $(\mathrm{mg} / \mathrm{L}), C_{e}$ : Se concentration of the solution in equilibrium $(\mathrm{mg} / \mathrm{L}), m_{O P B}$ : mass of organic pillared bentonite.

\section{Results and discussion}

First of all, organo-inorgano pillared bentonite (OPB) searched by XRD and then understood that its quality is appropriate for remediation (Fig. 1). With bentonite modification, the organic and inorganic cations enter into montmorillonite interlayer. Its basal space increases with this addition.
The variation in the basal spacing points out the structural changes as a result of modification. The comparison of the XRD patterns before and after modification shows the structural variation. The first peak in Fig. 1 shows the montmorillonite peak.

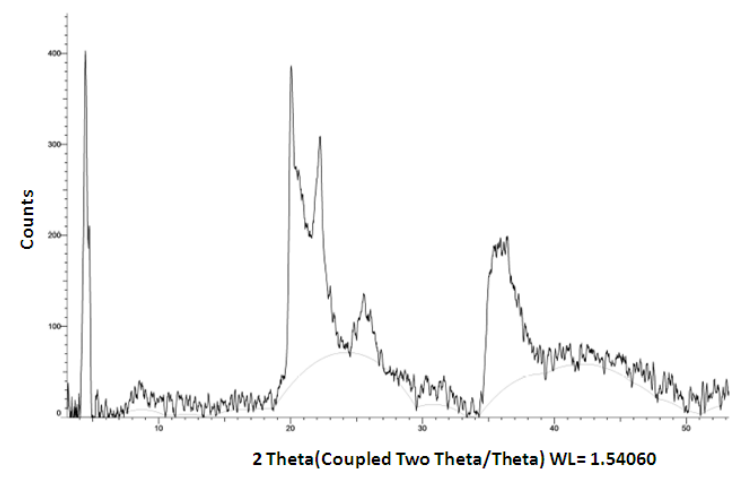

Fig. 1. XRD Analysis of OPB.

When it was compared with the montmorillonite peak of bentonite before modification [16], it was seen that the basal spacing increased from $1.11 \mathrm{~nm}$ to $1.92 \mathrm{~nm}$ and organic and inorganic cations entered into interlayer of montmorillonite mineral. The increase in basal spacing confirmed the effectiveness of the modification. XRD measurements confirmed the existence of positive organic and inorganic cations in the montmorillonite interlayer. These cations were effective in selenium adsorption onto bentonite surface. To study sorption equilibrium, selenium solutions containing 0.05 to $0.5 \mathrm{mg} / \mathrm{mL}$ were kept in contact with OPB for $2 \mathrm{~h}$ at $\mathrm{pH}$ 3.0. The results are shown in Fig. 2.

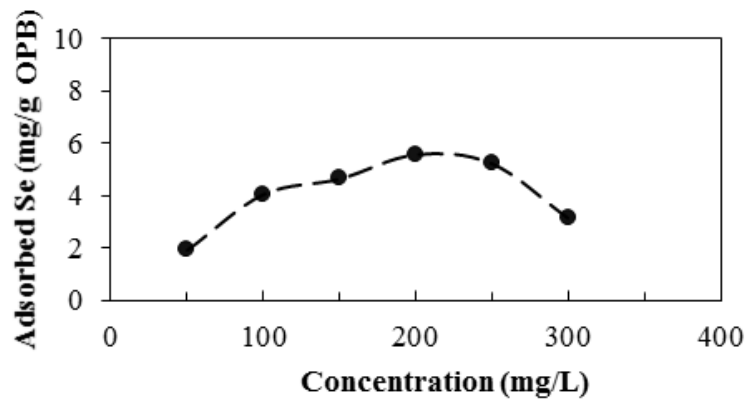

Fig. 2. The effect of initial concentration on the uptake of Se by OPB.

The amount of adsorbed Se increased with increasing initial selenium concentration in the aqueous solution to $0.2 \mathrm{mg} \mathrm{Se} / \mathrm{ml}$ and then decreased. Experimental data have shown that the Se(IV) in aqueous solution was properly removed by OPB.

$\mathrm{pH}$ is one of the most important parameters affecting ion sorption. Influence of $\mathrm{pH}$ values on the selenium adsorption onto OPB is given in Fig. 3 by keeping the conditions of $40 \mathrm{mg} \mathrm{OPB}, 20^{\circ} \mathrm{C}, 2 \mathrm{~mL}$ of $250 \mathrm{mg} / \mathrm{L} \mathrm{Se}(\mathrm{IV})$.

At low $\mathrm{pH}$ value, part of OPB might be dissolved in the solution. And that, a number of $\mathrm{H}^{+}$ions will occupy many adsorption sites which should belong to Se(IV). While a strange phenomenon can be seen in Fig. 2, that 
is the removal of $\mathrm{Se}(\mathrm{IV})$ would enhance when $\mathrm{pH}$ value is higher than 6.0. As seen in Fig. 3, the formation of various selenium complexes is important on the adsorption of $\mathrm{Se}(\mathrm{IV}) . \mathrm{H}_{2} \mathrm{SeO}_{3}, \mathrm{HSeO}_{3}^{-}$and $\mathrm{SeO}_{3}^{2-}$ complexes basically exists as a function of $\mathrm{pH}$ in selenium concentration under the experimental conditions in this study. $\mathrm{HSeO}_{3}^{-}$complex is the dominant species in the wide $\mathrm{pH}$ range from 1 to 10 . The dominant species in the range of $\mathrm{pH}$ lower than 4 is $\mathrm{H}_{2} \mathrm{SeO}_{3}$ complex [15]. Low removal amount at close to weak acidic region may be due to the anionic selenium complexes in solution. Charge repulsion may occur between ions and adsorbent, which would lead to the decrease of removal efficiency. Consequently, as shown in Fig. 2, the extent of sorption diminishes with the increase of $\mathrm{pH}$ from 1.0 to 6.6 .

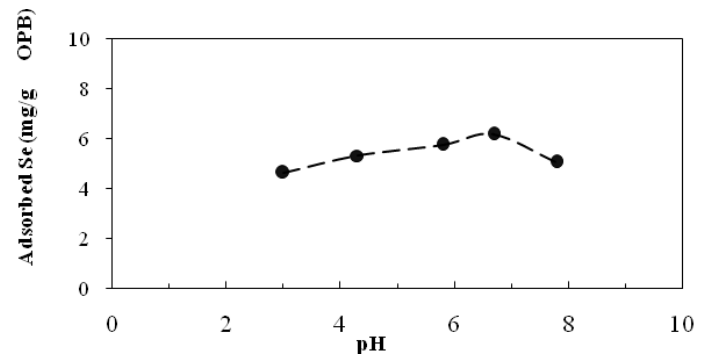

Fig. 3. The effect of $\mathrm{pH}$ values on the uptake of Se by OPB.

The effect of contact time on sorption was studied between 15 and 1560 min with fixed amounts of adsorbent (40 mg) at ambient temperature $\left(20^{\circ} \mathrm{C}\right)$ while keeping all other parameters constant. The results are presented in Fig. 3. As shown in Fig. 4, removal of selenium by OPB were increased with increasing time and reached equilibrium within 180 minutes. The selenium adsorption by the adsorbent reached a plateau after these contact intervals. For this reason, the optimum contact time was chosen as $180 \mathrm{~min}$. for organic pillared bentonite.

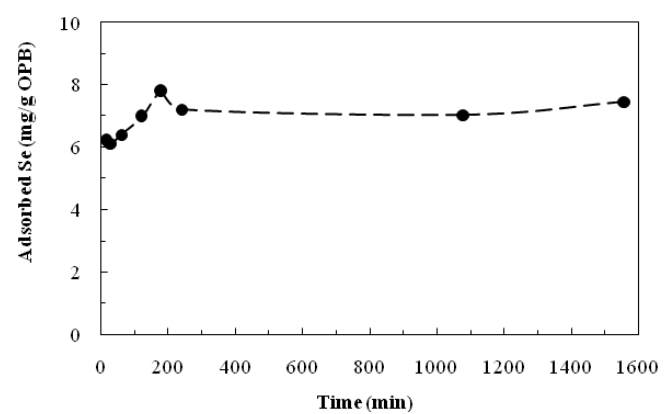

Fig. 4. The effect of contact time on the selenium uptake by OPB.

\section{Conclusion}

The present study focuses on adsorption of selenium from aqueous solutions using the organic pillared bentonite as a sorbent. The adsorption characteristic has been examined with the variations in the parameters of initial concentration of $\mathrm{Se}(\mathrm{IV}), \mathrm{pH}$ value and contact time. Modified bentonite has been demonstrated to be effective for the removal of the Se(IV) ions from aqueous solutions. The sorption equilibrium was attained within a time of $180 \mathrm{~min}$.

The results provide information for the remediation of $\mathrm{Se}(\mathrm{IV})$ and its species in natural surface and groundwater. The experimental data of this study indicate that modified bentonite can be used to remove toxic $\mathrm{Se}(\mathrm{IV})$ ions from aqueous solutions or wastewaters under optimized conditions.

\section{Acknowledgments}

We are grateful to the ITU TRIGA Mark-II Training and Research Reactor group for their helps during the irradiation of selenium

\section{References}

[1] A. Bidari, E.Z. Jahromi, Y. Assadi, M.R. Milani Hosseini, Microchemical Journal 87, 6 (2007).

[2] N. Zhang, L.S. Lin, D. Gang, Water Research 42, 3809 (2008)

[3] V. Chand, S. Prasad, Journal of Hazardous Materials 165, 780 (2009).

[4] M. Tuzen, A. Sarı, Chemical Engineering Journal 158, 200 (2010).

[5] L. Zhang, N. Liu, L. Yang, Q. Lin, Journal of Hazardous Materials 170, 1197 (2009).

[6] E.I. El-Shafey, Journal of Environmental Management 84, 620 (2007).

[7] E.I. El-Shafey, Journal of Hazardous Materials 147, 546 (2007).

[8] B.D. Wake, A.R. Bowie, E.C.V. Butler, P.R. Haddad, Trends in Analytical Chemistry 23, 491 (7).

[9] N.M. Najafi, S. Seidi, R. Alizadeh, H. Tavakoli, Spectrochimica Acta Part B 65, 334 (2010).

[10] N. Bleiman, Y.G. Mishael, Journal of Hazardous Materials 183, 590 (2010).

[11] G. Erdtmann, H. Petri in: Nuclear Activation Analysis Fundamentals and Techniques, Treatise of Analytical Chemistry, Part I, Vol. 14, 2nd Edition, ed. P.J. Elving, Wiley, New York, 1986.

[12] Z.B. Alfassi in: Activation Analysis, Vol. II, CRC, 1990.

[13] R.B. Firestone, Table of Isotopes (electronic resource) F. Chu , CD-ROM eds, 8th ed., update, Wiley, New York, 1998.

[14] S. Haciyakupoglu, S. Akyil Erentürk, N. Karatepe, A.B. Tuğrul, F. Baytaş, N. Altinsoy, N. Baydoğan, B. Buyuk, E. Demir, pp. 940-949, Global Conference on Global Warming GCGW-(2012), Istanbul-Turkey, 8-12 July 2012.

[15] A B. Tuğrul, S. Haciyakupoğlu, S. Akyıl Erentürk, N. Karatepe, A.F. Baytaş, N. Altinsoy, N. Baydoğan, B. Büyük, E. Demir in: Impacts and Solutions to Global Warming, Chapter 19, pp. 305-322, Springer, 2013.

[16] S. Haciyakupoglu, E. Orucoglu, Appl. Clay Sci. 86, 190 (2013). 